\title{
Modulating affect, cognition, and behavior - prospects of deep brain stimulation for treatment-resistant psychiatric disorders
}

\author{
Thomas E. Schlaepfer ${ }^{1,2}{ }^{*}$, Bettina Bewernick ${ }^{1}$, Sarah Kayser ${ }^{1}$ and Diane Lenz ${ }^{1}$ \\ 1 Brain Stimulation Group, Department of Psychiatry and Psychotherapy, University of Bonn, Bonn, Germany \\ ${ }^{2}$ Department of Psychiatry and Behavioral Science, The Johns Hopkins University, Baltimore, MD, USA
}

Edited by:

Chiara Saviane, Scuola Internazionale

Superiore di Studi Avanzati, Italy

\section{Reviewed by:}

Nir Lipsman, University of Toronto University Health Network, Canada Bruno Millet, Rennes 1 University, France

\section{*Correspondence:}

Thomas E. Schlaepfer, Department of Psychiatry, University Hospital,

Sigmund-Freud-Strasse 25, 53105

Bonn, Germany.

e-mail: schlaepf@jhmi.edu
Most patients suffering from psychiatric disorders respond to combinations of psycho- and psychopharmacotherapy; however there are patients who profit little if anything even after many years of treatment. Since about a decade different modalities of targeted neuromodulation - among them most prominently - deep brain stimulation (DBS) - are being actively researched as putative approaches to very treatment-resistant forms of those disorders. Recently, promising pilot data have been reported both for major depression (MD) and obsessive-compulsive disorder (OCD). Given the fact that patients included in DBS studies had been treated unsuccessfully for many years with conventional treatment methods, renders these findings remarkable. Remarkable is the fact, that in case of the long-term studies underway for MD, patients show a stable response. This gives hope to a substantial percentage of therapy-resistant psychiatric patients requiring new therapy approaches. There are no fundamental ethic objections to its use in psychiatric disorders, but until substantial clinical data is available, mandatory standards are needed. DBS is a unique and very promising method for the treatment of therapy-resistant psychiatric patients. The method allows manipulating pathological neuronal networks in a very precise way.

Keywords: major depression, obsessive-compulsive disorder, deep brain stimulation

\section{INTRODUCTION}

\section{PRINCIPLE, SAFETY, AND ADVANTAGES OF DBS}

Different modalities of neuromodulation such as repetitive transcranial magnetic stimulation (Schlaepfer et al., 2003; George, 2010), vagus nerve stimulation (Kosel and Schlaepfer, 2003; Schlaepfer et al., 2008b), and magnetic seizure therapy (Lisanby et al., 2001; Kayser et al., 2010) have been proposed and systematically studied in psychiatric different disorders (Schlaepfer et al., 2010). Both clinically and scientifically the most promising method of neuromodulation might be deep brain stimulation (DBS). DBS refers to the stereotaxic placement of unilateral or bilateral electrodes connected to a permanently implanted neurostimulator (Schlaepfer and Lieb, 2005b). The exact neurobiological mechanisms by which DBS exerts effects on brain tissue are not yet fully understood (Hardesty and Sackeim, 2007). Various mechanisms have been discussed, on the neuronal level, excitatory and inhibitory processes might play a role (McIntyre et al., 2004). Most probably, DBS leads to a functional lesion of the surrounding tissue. Today, it is unknown which part of the neuron (e.g., cell body, axon) is primarily modulated by DBS. Certainly, the stimulation volume is not a fixed area around the electrode and the effect on neuronal tissue is variable. Stimulation parameters (frequency, amplitude, pulse width, duration) also clearly have an impact on the effect (Ranck, 1975). With commonly used parameters, a relatively large volume of neural tissue is influenced (Kringelbach et al., 2007).
Side effects in DBS are either related to the operation itself (e.g., bleeding, local infections at the chest) or to the stimulation (e.g., elevation of mood, anxiety, motor slowing). Fortunately, the safety of the stereotactic operation technique has been extremely improved in the last years with the help of neuroimaging. Bleeding rate of DBS surgeries are between 0.2 and 5\% (Kosel et al., 2007; Kühn et al., 2007). On the other hand, DBS has many advantages over traditional therapy methods: clinical effects can be achieved without irreversible lesioning, stereotactic operation is the most minimal neurosurgical method and electrodes can be completely removed if necessary. Brain activity can be changed in a direct, controlled manner. Furthermore, DBS offers the opportunity to continuously adjust stimulation variables for each patient in order to optimize therapy. The patient can turn off stimulation immediately if side effects occur. DBS is the only neurosurgical method that allows blinded studies for therapy control. In comparison to antidepressant medication, nor side effects such as extrapyramidal effects, weight gain, that substantially effect compliance and patient's quality of life, are reported. Also no long-time side effects as in antidepressant treatments (Geddes et al., 2003; Furukawa et al., 2007) have been reported. Nonetheless, DBS can be associated with side effects due to stimulation that are transient and can be counteracted by a change in stimulation parameters (see Table 1). But until it has been proven that DBS has the same clinical effect as pharmacotherapy, the latter together with psychotherapy must be the first treatment choice. 
Table 1 | Possible side effects of DBS in OCD or depression.

\begin{tabular}{ll}
\hline Negative effects of DBS & Positive effects of DBS \\
\hline $\begin{array}{ll}\text { For example, bleeding or local } \\
\text { infections at the chest caused }\end{array}$ & $\begin{array}{l}\text { Clinical effects can be achieved without } \\
\text { irreversible lesioning } \\
\text { by the operation itself }\end{array}$ \\
For example, elevation of & Electrodes can be completely removed \\
mood, anxiety, motor slowing & if necessary
\end{tabular}

Brain activity can be changed in a direct, controlled manner

Opportunity to continuously adjust stimulation variables for each patient individually The patient can turn off stimulation immediately if side effects occur Allows blinded studies for therapy control No extrapyramidal effects

No weight gain

No long-time side effects as in

antidepressant treatments are reported

Thus, DBS could become an exciting method in the treatment of depression and obsessive-compulsive disorder (OCD) and offers unique possibilities to gain more insight into the underlying neurobiology of psychiatric disorders.

\section{FIRST EFFICACY RESULTS IN OCD AND DEPRESSION}

The main focus of studies on the underlying neurobiology of major depression (MD) has focused on the description of biological differences between patients and healthy subjects such as alterations of monoaminergic or endocrine systems. The relative importance of the various biological changes has not been elucidated; correlation with specific symptoms of the disease has rarely been attempted. Psychotropic drugs work by altering neurochemistry to a large extent in widespread regions of the brain, many of which may be unrelated to depression.

In contrast to some neurological disorders, the pathological interplay of several brain regions contributes to the behavioral, emotional, and cognitive symptoms of psychiatric disorders. Metabolic studies suggest that different symptoms are mediated by different brain regions (Berton and Nestler, 2006; YurgelunTodd et al., 2007; Krishnan and Nestler, 2008) A convincing network-model of depression integrating biochemical, electrophysiological, imaging, and animal studies, has been described by Mayberg (1997). According to this model, depression results from a dysregulation of limbic-cortical connections: pathological changes in dorsal brain regions (including the dorsolateral prefrontal cortex, inferior parietal cortex, and striatum) were associated with cognitive symptoms (e.g., apathy, anhedonia, hopelessness, deficits in attention, and executive function), changes in ventral areas (hypothalamic-pituitary-adrenal axis, Insula, subgenual cingulate, and brainstem) contribute to the vegetative and somatic aspects of depression (e.g., sleep disturbance, appetite, endocrine dysregulation). This model underlines the role of the rostral cingulate cortex in regulating the network (Mayberg, 1997). The involvement of further regions in depression is discussed: the hippocampus contributes to memory deficits, the nucleus accumbens was associated with anhedonia and lack of motivation, the amygdala plays a role in the processing of aversive stimuli and avoidance (Berton and Nestler, 2006).

Obsessive-compulsive disorder is characterized by obsessions (anxiety-provoking thoughts) and compulsions (repeated, timeconsuming behaviors; Stein, 2002). As in most psychiatric disorders, a complex interplay of genetic factors, neurotransmitter changes and psychosocial characteristics contribute to the development of this disease. Changes in dopamine and serotonin have been reported (Stein, 2002). Dysfunctions in a network connecting the cortex and basal ganglia are supposed to underlie OCD. Imaging data demonstrated changes in orbitofrontal cortex, anterior cingulate cortex and caudate nucleus in OCD (Baxter, 1990). Emerging evidence suggests that different alternations of the OCD circuitry subserve different symptom subtypes (Kopell and Greenberg, 2008). It has been hypothesized that an over activation of the direct pathway of the cortico-striatal-pallidal-thalamic-cortical loop leads to intrusive thoughts (Baxter et al., 2001).

These novel conceptualizations of both OCD and MD, brought about mainly by advances in functional neuroimaging but also electrophysiological and molecular studies and their synthesis have paved the road to hypothesis-guided studies on targeted reversible neuromodulation with DBS in these disorders.

The subgenual cingulate cortex (Brodmann Area cg25) has probably dysfunctional connections to the dorsal and ventral compartments of the emotion regulation circuit in depression (Mayberg, 1997). The subgenual cingulate cortex modulates negative mood states (Mayberg et al., 2005b). It has been involved in acute sadness and in antidepressive treatment effects (Mayberg et al., 2005a; Lozano et al., 2008). The rostral part of the cingulate cortex seems to play a key role in modulating the network of depression (Mayberg, 1997).

Mayberg et al. (2005b) could demonstrate, that 2 months after surgery, 5/6 patients met the response criterion [baseline score in the Hamilton Depression Rating Scale (HDRS) minus 50\%], after 6 months, four patients showed sustained response. Different neuropsychological parameters that were impaired at baseline were significantly improved. A reduction in the pathological hyperactivity in this region has also been demonstrated using positron emission tomography (PET) in this study. During the blinded sham stimulation phase $(n=1)$, the patient's condition worsened considerably. No adverse events due to stimulation were observed (Mayberg et al., 2005b).

Malone et al. (2009) investigated the use of DBS at the ventral capsule/ventral striatum (VC/VS). The VC/VS was targeted, because former studies targeting the VC/VS in OCD patients (Nuttin et al., 1999; Greenberg et al., 2006) showed improvement not only for OCD symptoms but also for depressive symptoms. This finding was supported by the fact that the VS has complex architecture and includes structures such as the bed nucleus of the stria terminalis and the nucleus accumbens, which are regions believed to be involved with stress-related and reward-motivation components of depression (Forray and Gysling, 2004; Epstein et al., 2006). Once stimulation was titrated to therapeutic benefit and the absence of adverse effects, patients received significant improvements in depressive symptoms measured by the HDRS. 
Responder rates of $40 \%$ at 6 months $(n=15)$ and $53.3 \%$ at last follow-up (mean last follow-up of $23.5 \pm 14.9$ months) receiving continuous DBS stimulation are referred. Remission rates were reported $20 \%$ at 6 months and $40 \%$ at last follow-up with the HDRS. So the results of this study suggest that DBS of the VC/VS could also provide benefit in highly treatment-refractory patients with depression. However, since the larger contacts of the VC/VS leads have twice the surface area of standard leads used in other DBS applications, more frequent battery replacements or rather implanting recharging batteries should be considered (Malone et al., 2009).

We selected the Nucleus Accumbens as target for DBS because of its prominent role in the reward system. The Nucleus accumbens is known to act as motivational gateway between systems involved in motor control and limbic systems in charge of emotion processing; especially the ventral striatum is uniquely located to modulate other regions of the brain (Schlaepfer et al., 2008a). By targeting one site in a network of brain regions implicated in processing of affective stimuli, it was possible to manipulate anhedonia in particular. It could be demonstrated that modulation of this structure was associated with changes in the symptoms of anhedonia and mood in three depressed patients. Stimulation current correlated negatively with anhedonia ratings. Normalization of brain metabolism in fronto-striatal networks as result of stimulation was also observed (Schlaepfer et al., 2008a). It is notable, that no side effects due to stimulation were observed. Results from a total of nine patients in this study show acute as well as long-term antidepressant effects of DBS at this target have been published recently, demonstrating a responder rate of 50\% (Bewernick et al., 2010).

The habenula has been proposed recently as target for DBS in depression (Sartorius and Henn, 2007). Animal data and imaging studies have shown, that this regions controls serotonergic fibers from the dorsal raphe nuclei and noradrenergic fibers from the locus coeruleus (Winter et al., 2011). The authors hypothesize that over activation of the habenula is related to depression and recently reported on the course of depression after DBS to the habenula in a case report (Sartorius et al., 2010).

Another putative target site for $\mathrm{MD}$ has been proposed very recently, the medial forebrain bundle (Coenen et al., 2011). Magnetic resonance diffusion tensor imaging (DTI) can visualize distinct functional circuits in the living human brain on the basis of the anisotropy of the brain tissue. This technique has been applied to an analysis of the different DBS sites for MD and lead to the hypothesis-guided development of yet another site with hypothetically greater efficacy and even less unwanted effects. Pilot studies assessing clinical efficacy are underway.

Single-case studies in OCD patients with comorbid depression have shown antidepressant effects: bilateral stimulation of the ventral nucleus caudatus in combination with Nucleus Accumbens for OCD led to remission of depression (HDRS_17 $<7$ ) after 6 month. No neuropsychological deterioration was reported (Aouizerate et al., 2004).

It was supposed that dysregulation of the connection between unspecific thalamic system and orbitofrontal cortex plays an important role in the development of depression (Jiménez et al., 2005). Therefore, bilateral stimulation of the lower thalamus stem was performed one depressed patient and led to remission (HDRS $42 \rightarrow 10$ ). The effect remained stable for 24 months. During blinded discontinuation of stimulation, the patient's condition aggravated (Jiménez et al., 2005).

In OCD, there have been proposed different targets according to the underlying pathological network. The orbitofrontal cortex and the anterior cingulate cortex are part of the OCD circuit. Unfortunately, these regions are very large and not well circumscribed in relation to this disease. Thus the size of cortex region that needs to be modulated would be too large (Lipsman et al., 2007). In most studies, the anterior limb of the internal capsule was the target for either unilateral or bilateral stimulation (Anderson and Ahmed, 2003; Gabriels et al., 2003; Nuttin et al., 1999; Nuttin et al., 2003; Sturm et al., 2003). All studies reported on promising results ranging from response to complete remission. In terms of side effects, some studies reported on induced, directly stimulation related symptoms of hypomania which all ceased completely after reduction of stimulation intensity.

The Nucleus thalamicus - zona incerta has been studied at three patients with Parkinson's disease and comorbid OCD (Mallet et al., 2002; Fontaine et al., 2004). Both studies reported considerable amelioration of OCD symptoms. The subthalamic nucleus was stimulated in a study (Malone et al., 2009), this group included 16 patients and received significant lower symptoms of OCD. In a recent OCD study targeting the subthalamic nucleus, OCD symptoms were significantly reduced after the 3 -months double-blind stimulation phase compared to the double-blind sham stimulation phase (Mallet et al., 2008). Both studies refer to possible associated risk of serious adverse events (Mallet et al., 2008; Malone et al., 2009). The Nucleus Accumbens and Nucleus Caudatus were target in one case study with comorbid depression (s above). This patient achieved remission status (Aouizerate et al., 2004). Unilateral stimulation of the NAcc in a well-designed, controlled study lead to somewhat less impressive but significant improvements results in 10 patients (Huff et al., 2010). The stimulation of the VC/VS led to a significant improvement in $50 \%$ of the patients (Greenberg et al., 2006). Side effects related to the stimulation were transient hypomania and increased anxiety, which could be counteracted by parameter change (Greenberg et al., 2006).

Recently results of bilateral DBS to the Nucleus Accumbens in OCD with an open 8-month treatment phase, followed by a double-blind crossover phase with randomly assigned 2-week periods of active or sham stimulation, ending with an open 12month maintenance phase have been published (Denys et al., 2010). Nine of the 16 patients were classified as responders, indicating that bilateral stimulation of the nucleus accumbens may be an effective and safe treatment in patients with highly refractory OCD.

In summary, promising effects for different targets have been demonstrated, but as worldwide sample sizes are small, it is too early to select one favorable target if there is any. As OCD is a heterogeneous disease, there might be different optimal targets for different symptom clusters.

\section{ETHICAL ISSUES}

Introducing a new invasive therapeutic approach requires evaluation according to high ethical standards. The high mortality, 
low quality of life, and the social burden of inadequately treated serious psychiatric illness favor the use of DBS for treatmentresistant patients. The potential benefit to the understanding of pathological principles in mental disorders is evident (Schlaepfer and Lieb, 2005a; Fuchs, 2006; Ford, 2007; Synofzik and Schlaepfer, 2008, 2010).

Fundamental ethical concerns are generally applicable to all clinical interventions (e.g., pharmacotherapy, psychotherapy) including DBS in neurological disorders. Foremost, are patients able to give conformed consent? It has been demonstrated that depressed patients show few impairments in decision-making capacity related to clinical treatment research (Appelbaum et al., 1999). Another concern is, how far human nature may ethically be manipulated (Fuchs, 2006). Long-term effects of DBS cannot be evaluated yet, but in comparison to pharmacotherapy, brain stimulation is a more specific and reversible intervention. No harmful effects are reported so far. More problematic is the danger of misuse, such as for mind control or for over-enhancement of normal (healthy) cognitive function ("brain doping"; Fuchs, 2006; Ford, 2007). As clinical researchers in psychiatry, our aim is to help patients to lead a normal life, including normal cognitive function and personal autonomy.

More practical ethical concerns are the availability of alternative treatment methods (e.g., pharmacotherapy, ECT, psychotherapy). Taking to account that DBS is used only with treatment-resistant patients, who have already shown no benefit with other treatment approaches currently available, the apparent reversibility of DBS and its robust potential benefits, as described by prior pilot studies, are strong ethical arguments for considering DBS treatment for resistant psychiatric disorders (Synofzik and Schlaepfer, 2008, 2010).

However, there are also some notable risks with DBS, particularly intracerebral bleeding and wound infection and its efficacy is not yet formally and extensively established in controlled trials. Therefore, until the DBS treatment method is scientifically validated; obligatory standards for patient inclusion and exclusion criteria as well as the selection of targets are needed. Partly this has been already described by Rabins et al. (2009), recommending 16 key points for guiding research and protecting the safety and rights of research subjects, as well as Nuttin et al. (2002) advocating certain minimum requirements for using DBS in psychiatric conditions. Whereas we question the suggestion of Nuttin et al. (2002) to form a separate committee with only distant access to the individual patient or no direct involvement to the study for reviewing patient selection. It is our belief, that despite any committee

\section{REFERENCES}

Anderson, D., and Ahmed, A. (2003). Treatment of patients with intractable obsessive-compulsive disorder with anterior capsular stimulation. Case report. J. Neurosurg. 98, 1104-1108.

Aouizerate, B., Cuny, E., Martin-Guehl, C., Guehl, D., Amieva, H., Benazzouz, A., Fabrigoule, C., Allard, M., Rougier, A., Bioulac, B., Tignol, J., and Burbaud, P. (2004). Deep brain stimulation of the ventral caudate nucleus in the treatment of obsessive-compulsive disorder and major depression. Case report. J. Neurosurg. 101, 574-575.

Appelbaum, P. S., Grisso, T., Frank, E., O'Donnell, S., and Kupfer, D. J. (1999). Competence of depressed patients for consent to research. Am. J. Psychiatry 156, 1380-1384.

Baxter, L. R. (1990). Brain imaging as a tool in establishing a theory of

review - might it be as thorough and exhaustive as possible the clinical responsibility remains with the patient's clinicians and cannot be shared by review committees. So from our point of view further research regarding obligatory standards in DBS is needed.

Another possible event to consider is the risk of selective publishing of results. This is by no means unique to DBS, but this area is particularly vulnerable to bias because of an excessive reliance on single-patient case reports (Schlaepfer and Fins, 2010). Until cohort studies are routinely performed, the possibility will remain that only positive results will be published at the expense of negative data that might also have important implications. Balanced publishing of results is even more important taking to account, that patients and public understanding of the risks and benefits of DBS is strongly shaped by media (Racine et al., 2007).

\section{DISCUSSION}

A substantial percentage of therapy-resistant psychiatric patients require new therapy approaches. DBS offers the possibility to manipulate pathological neuronal networks in a very precise way. First studies showed very promising effects in depression and OCD. There are no fundamental ethic objections to its use in psychiatric disorders, but until substantial clinical data is available, mandatory standards are needed for patient and target selection, quality of research center, and study protocol. It is very important to point out that in the actual stage of research; DBS for psychiatric diseases is clinical research on therapeutics. The benefit of this method has to be proven first, until DBS will be available for many patients. Before, much more information about the therapeutic effect, individual predictors of response, possible short and long-time side effects, and neuroethical issues have to be gained.

Deep brain stimulation is a unique and very promising method for the treatment of therapy-resistant psychiatric patients. Nonetheless, the duration of the battery limits the choice of stimulation parameters, increases the risk of infection, and raises treatment costs. Rechargeable batteries are currently being introduced to the field. Actual technology allows mainly continuous stimulation with little possibility for dynamic adjustment. A particular advantage of DBS is, that it allows recording signals from the stimulating electrodes (Cohen et al., 2009a,b,c) and combining these data with functional neuroimaging in order to map the spatiotemporal unfolding of DBS-elicited whole brain activity will lead to a much broader knowledge on functional and dysfunctional circuits processing affective stimuli revealing fundamental mechanisms of brain function.

brain pathology in obsessive compulsive disorder. J. Clin. Psychiatry 51(Suppl. ), 22-25; discussion 26.

Baxter, L. R. J., Clark, E. C., Iqbal, M., and Ackermann, R. F. (2001). "Cortical-subcortical systems in the mediation of OCD: modeling the brain's mediation of a classic "neurosis"," in FrontalSubcortical Circuits in Psychiatric and Neurological Disorders, eds D. G. Lichter and J. L. Cummings
(New York: Guilford Press) 207-230.

Berton, O., and Nestler, E. J. (2006). New approaches to antidepressant drug discovery: beyond monoamines. Nat. Rev. Neurosci. 7, 137-151.

Bewernick, B. H., Hurlemann, R., Matusch, A., Kayser, S., Grubert, C., Hadrysiewicz, B., Axmacher, N., Lemke, M., Cooper-Mahkorn, D., Cohen, M. X., Brockmann, H., Lenartz, D., Sturm, V., and 
Schlaepfer, T. E. (2010). Nucleus accumbens deep brain stimulation decreases ratings of depression and anxiety in treatmentresistant depression. Biol. Psychiatry 67, 110-116.

Coenen, V. A., Schlaepfer, T. E., Maedler, B., and Panksepp, J. (2011). Cross-species affective functions of the medial forebrain bundle-implications for the treatment of affective pain and depression in humans. Neurosci. Biobehav. Rev. doi: 10.1016/j.neubiorev.2010. 12.009

Cohen, M. X., Axmacher, N., Lenartz, D., Elger, C. E., Sturm, V., and Schlaepfer, T. E. (2009a). Good vibrations: cross-frequency coupling in the human nucleus accumbens during reward processing. J. Cogn. Neurosci. 21, 875-889.

Cohen, M. X., Axmacher, N., Lenartz, D., Elger, C. E., Sturm, V., and Schlaepfer, T. E. (2009b). Neuroelectric signatures of reward learning and decision-making in the human nucleus accumbens. Neuropsychopharmacology 34, 1649-1658.

Cohen, M. X., Axmacher, N., Lenartz, D., Elger, C. E., Sturm, V., and Schlaepfer, T. E. (2009c). Nuclei accumbens phase synchrony predicts decision-making reversals following negative feedback. $J$. Neurosci. 29, 7591-7598.

Denys, D., Mantione, M., Figee, M., van den Munckhof, P., Koerselman, F., Westenberg, H., Bosch, A., and Schuurman, R. (2010). Deep brain stimulation of the nucleus accumbens for treatmentrefractory obsessive-compulsive disorder. Arch. Gen. Psychiatry 67, 1061-1068.

Epstein, J., Pan, H., Kocsis, J. H., Yang, Y., Butler, T., Chusid, J., Hochberg, H., Murrough, J., Strohmayer, E., Stern, E., and Silbersweig, D. A. (2006). Lack of ventral striatal response to positive stimuli in depressed versus normal subjects. Am. J. Psychiatry 163, 1784-1790.

Fontaine, D., Mattei, V., Borg, M., von Langsdorff, D., Magnie, M. N., Chanalet, S., Robert, P., and Paquis, P. (2004). Effect of subthalamic nucleus stimulation on obsessivecompulsive disorder in a patient with Parkinson disease. Case report. J. Neurosurg. 100, 1084-1086.

Ford, P. J. (2007). Neurosurgical implants: clinical protocol considerations. Camb. Q. Healthc. Ethics 16, 308-311.

Forray, M. I., and Gysling, K. (2004). Role of noradrenergic projections to the bed nucleus of the stria terminalis in the regulation of the hypothalamic-pituitary-adrenal axis. Brain Res. Brain Res. Rev. 47, 145-160.

Fuchs, T. (2006). Ethical issues in neuroscience. Curr Opin Psychiatry 19, 600-607.

Furukawa, T. A., Cipriani, A., Barbui, C., and Geddes, J. R. (2007). Longterm treatment of depression with antidepressants: a systematic narrative review. Can. J. Psychiatry 52, 545-552.

Gabriels, L., Cosyns, P., Nuttin, B., Demeulemeester, H., and Gybels, J. (2003). Deep brain stimulation for treatment-refractory obsessivecompulsive disorder: psychopathological and neuropsychological outcome in three cases. Acta Psychiatr. Scand. 107, 275-282.

Geddes, J. R., Carney, S. M., Davies, C., Furukawa, T. A., Kupfer, D. J., Frank, E., and Goodwin, G. M. (2003). Relapse prevention with antidepressant drug treatment in depressive disorders: a systematic review. Lancet 361, 653-661.

George, M. S. (2010). Transcranial magnetic stimulation for the treatment of depression. Expert Rev. Neurother. 10, 1761-1772.

Greenberg, B. D., Malone, D. A., Friehs, G. M., Rezai, A. R., Kubu, C. S., Malloy, P. F., Salloway, S. P., Okun, M. S., Goodman, W. K., and Rasmussen, S. A. (2006). Three-year outcomes in deep brain stimulation for highly resistant obsessive-compulsive disorder. Neuropsychopharmacology 31, 2384-2393.

Hardesty, D. E., and Sackeim, H. A. (2007). Deep brain stimulation in movement and psychiatric disorders. Biol. Psychiatry 61, 831-835.

Huff, W., Lenartz, D., Schormann, M., Lee, S. H., Kuhn, J., Koulousakis, A., Mai, J., Daumann, J., Maarouf, M., Klosterkotter, J., and Sturm, V. (2010). Unilateral deep brain stimulation of the nucleus accumbens in patients with treatmentresistant obsessive-compulsive disorder: outcomes after one year. Clin. Neurol. Neurosurg. 112, 137-143.

Jiménez, F., Velasco, F., Salin-Pascual, R., Hernández, J. A., Velasco, M., Criales, J. L., and Nicolini, H. (2005). A patient with a resistant major depression disorder treated with deep brain stimulation in the inferior thalamic peduncle. J. Neurosurg. 57, 585-593.

Kayser, S., Bewernick, B. H., Grubert, C., Hadrysiewicz, B. L., Axmacher, N., and Schlaepfer, T. E. (2010). Antidepressant effects, of magnetic seizure therapy and electroconvulsive therapy, in treatment-resistant depression. J. Psychiatr. Res. 45, 569-576.

Kopell, B. H., and Greenberg, B. D. (2008). Anatomy and physiology of the basal ganglia: implications for DBS in psychiatry. Neurosci. Biobehav. Rev. 32, 408-422.

Kosel, M., and Schlaepfer, T. E. (2003). Beyond the treatment of epilepsy: new applications of vagus nerve stimulation (VNS) in psychiatry. CNS Spectr. 8, 515-521.

Kosel, M., Sturm, V., Frick, C., Lenartz, D., Zeidler, G., Brodesser, D., and Schlaepfer, T. E. (2007). Mood improvement after deep brain stimulation of the internal globus pallidus for tardive dyskinesia in a patient suffering from major depression. J. Psychiatr. Res. 41, 801-803.

Kringelbach, M. L., Jenkinson, N., Owen, S. L., and Aziz, T. Z. (2007). Translational principles of deep brain stimulation. Nat. Rev Neurosci. 8, 623-635.

Krishnan, V., and Nestler, E. J. (2008). The molecular neurobiology of depression. Nature 455, 894-902.

Kühn, J., Huff, W., Lee, S.-H., Lenartz, D., Sturm, V., and Klosterkötter, J. (2007). Tiefenhirnstimulation bei psychiatrischen Erkrankungen. Fortschr. Neurol. Psychiatr. 75, 447-457.

Lipsman, N., Neimat, J. S., and Lozano, A. M. (2007). Deep brain stimulation for treatment-refractory obsessive-compulsive disorder: the search for a valid target. Neurosurgery $61,1-11$; discussion 11-13.

Lisanby, S. H., Schlaepfer, T. E., Fisch, H. U., and Sackeim, H. A. (2001). Magnetic seizure therapy of major depression. Arch. Gen. Psychiatry 58, 303-305.

Lozano, A. M., Mayberg, H. S., Giacobbe, P., Hamani, C., Craddock, R. C., and Kennedy, S. H. (2008). Subcallosal cingulate gyrus deep brain stimulation for treatmentresistant depression. Biol. Psychiatry 64, 461-467.

Mallet, L., Mesnage, V., Houeto, J. L., Pelissolo, A., Yelnik, J., Behar, C., Gargiulo, M., Welter, M. L., Bonnet, A. M., Pillon, B., Cornu, P., Dormont, D., Pidoux, B., Allilaire, J. F., and Agid, Y. (2002). Compulsions, Parkinson's disease, and stimulation. Lancet 360, 1302-1304

Mallet, L., Polosan, M., Jaafari, N., Baup, N., Welter, M. L., Fontaine, D., du Montcel, S. T., Yelnik, J., Chereau, I., Arbus, C., Raoul, S., Aouizerate, B., Damier, P., Chabardes, S.,
Czernecki, V., Ardouin, C., Krebs, M. O., Bardinet, E., Chaynes, P., Burbaud, P., Cornu, P., Derost, P., Bougerol, T., Bataille, B., Mattei, V., Dormont, D., Devaux, B., Verin, M., Houeto, J. L., Pollak, P., Benabid, A. L., Agid, Y., Krack, P., Millet, B., and Pelissolo, A. (2008). Subthalamic nucleus stimulation in severe obsessive-compulsive disorder. $N$. Engl. J. Med. 359, 2121-2134.

Malone, D. A. Jr., Dougherty, D. D., Rezai, A. R., Carpenter, L. L., Friehs, G. M., Eskandar, E. N., Rauch, S. L., Rasmussen, S. A., Machado, A. G., Kubu, C. S., Tyrka, A. R., Price, L. H., Stypulkowski, P. H., Giftakis, J. E., Rise, M. T., Malloy, P. F., Salloway, S. P., and Greenberg, B. D. (2009). Deep brain stimulation of the ventral capsule/ventral striatum for treatmentresistant depression. Biol. Psychiatry. $65,267-275$.

Mayberg, H., Lozano, A., Voon, V., McNeely, H., Seminowicz, D., Hamani, C., Schwalb, J., and Kennedy, S. (2005a). Deep brain stimulation for treatment-resistant depression. Neuron 45, 651-660.

Mayberg, H. S., Lozano, A. M., Voon, V., McNeely, H. E., Seminowicz, D., Hamani, C., Schwalb, J. M., and Kennedy, S. H. (2005b). Deep brain stimulation for treatment-resistant depression. Neuron 45, 651-660.

Mayberg, H. S. (1997). Limbic-cortical dysregulation: a proposed model of depression. J. Neuropsychiatry Clin. Neurosci. 9, 471-481.

McIntyre, C. C., Savasta, M., KerkerianLe Goff, L., and Vitek, J. L. (2004) Uncovering the mechanism(s) of action of deep brain stimulation activation, inhibition, or both. Clin. Neurophysiol. 115, 1239-1248.

Nuttin, B., Cosyns, P., Demeulemeester, H., Gybels, J., and Meyerson, B. (1999). Electrical stimulation in anterior limbs of internal capsules in patients with obsessive-compulsive disorder. Lancet 354, 1526.

Nuttin, B., Gybels, J., Cosyns, P., Gabriels, L., Meyerson, B., Andreewitch, S., Rasmussen, S., Greenberg, B., Friehs, G., Rezai, A. R., Montgomery, E., Malone, D., and Fins, J. J. (2002). Deep brain stimulation for psychiatric disorders. Neurosurgery 51, 519.

Nuttin, B. J., Gabriels, L. A., Cosyns, P. R., Meyerson, B. A., Andreewitch, S., Sunaert, S. G., Maes, A. F., Dupont, P. J., Gybels, J. M., Gielen, F., and Demeulemeester, H. G. (2003). Long-term electrical capsular stimulation in patients with obsessive-compulsive disorder. Neurosurgery 52, 1263-1272; discussion 1272-1274. 
Rabins, P., Appleby, B., Brandt, J., DeLong, M., Dunn, L., Gabriëls, L., Greenberg, B., Haber, S., Holtzheimer, P., Mari, Z., Mayberg, H., McCann, E., Mink, S., Rasmussen, S., Schlaepfer, T., Vawter, D., Vitek, J., Walkup, J., and Mathews, D. (2009). Deep Brain Stimulation for Disorders of Mood, Behavior and Thought: Scientific and Ethical Issues. Arch. Gen. Psychiatry 66, 931-937.

Racine, E., Waldman, S., Palmour, N. Risse, D., and Illes, J. (2007). "Currents of hope": neurostimulation techniques in U.S. and U.K. print media. Camb. Q. Healthc. Ethics 16, 312-316.

Ranck, J. B. Jr. (1975). Which elements are excited in electrical stimulation of mammalian central nervous system: a review. Brain Res. 98, 417-440.

Sartorius, A., and Henn, F. A. (2007). Deep brain stimulation of the lateral habenula in treatment resistant major depression. Med. Hypotheses 69, 1305-1308.

Sartorius, A., Kiening, K. L., Kirsch, P., von Gall, C. C., Haberkorn, U., Unterberg, A. W., Henn, F. A., and Meyer-Lindenberg, A. (2010). Remission of major depression under deep brain stimulation of the lateral habenula in a therapyrefractory patient. Biol. Psychiatry 67, e9-e11.
Schlaepfer, T. E., Cohen, M. X., Frick, C., Kosel, M., Brodesser, D., Axmacher, N., Joe, A. Y., Kreft, M., Lenartz, D., and Sturm, V. (2008a). Deep brain stimulation to reward circuitry alleviates anhedonia in refractory major depression. Neuropsychopharmacology 33, 368-377.

Schlaepfer, T. E., Frick, C., Zobel, A., Maier, W., Heuser, I., Bajbouj, M., O'Keane, V., Corcoran, C., Adolfsson, R., Trimble, M., Rau, H., Hoff, H. J., Padberg, F., Muller-Siecheneder, F., Audenaert, K., Van den Abbeele, D., Stanga, Z., and Hasdemir, M. (2008b). Vagus nerve stimulation for depression: efficacy and safety in a European study. Psychol. Med. 38, 651-661.

Schlaepfer, T. E., and Fins, J. J. (2010). Deep brain stimulation and the neuroethics of responsible publishing: when one is not enough. JAMA 303, 775-776.

Schlaepfer, T. E., George, M. S., Mayberg, H., and WFSBP Task Force on Brain Stimulation. (2010). WFSBP guidelines on brain stimulation treatments in psychiatry. World J. Biol. Psychiatry 11, 2-18.

Schlaepfer, T. E., Kosel, M., and Nemeroff, C. B. (2003). Efficacy of repetitive transcranial magnetic stimulation (rTMS) in the treatment of affective disorders. Neuropsychopharmacology 28 201-205.

Schlaepfer, T. E., and Lieb, K. (2005a). Deep brain stimulation for treatment of refractory depression. Lancet 366, 1420-1422.

Schlaepfer, T. E., and Lieb, K. (2005b). Deep brain stimulation for treatment refractory depression. Lancet 366, 1420-1422.

Stein, D. J. (2002). Obsessivecompulsive disorder. Lancet 360, 397-405.

Sturm, V., Lenartz, D., Koulousakis, A., Treuer, H., Herholz, K., Klein, J. C., and Klosterkotter, J. (2003). The nucleus accumbens: a target for deep brain stimulation in obsessive-compulsive- and anxietydisorders. J. Chem. Neuroanat. 26, 293-299.

Synofzik, M., and Schlaepfer, T. (2010). Electrodes in the brain - ethical criteria for research and treatment with deep brain stimulation for neuropsychiatric disorders. Brain Stimul. 4, 7-16.

Synofzik, M., and Schlaepfer, T. E. (2008). Stimulating personality: ethical criteria for deep brain stimulation in psychiatric patients and for enhancement purposes. Biotechnol. J. 3, 1511-1520.

Winter, C., Vollmayr, B., Djodari-Irani, A., Klein, J., and Sartorius, A. (2011). Pharmacological inhibition of the lateral habenula improves depressive-like behavior in an animal model of treatment resistant depression. Behav. Brain Res. 216, 463-465.

Yurgelun-Todd, D. A., Sava, S., and Dahlgren, M. K. (2007). Mood disorders. Neuroimaging Clin. N. Am. 17, 511-521, ix.

Conflict of Interest Statement: The authors declare that the research was conducted in the absence of any commercial or financial relationships that could be construed as a potential conflict of interest.

Received: 31 January 2011; accepted: 14 June 2011; published online: 24 June 2011.

Citation: Schlaepfer TE, Bewernick B Kayser S and Lenz D (2011) Modulating affect, cognition, and behavior - prospects of deep brain stimulation for treatment-resistant psychiatric disorders. Front. Integr. Neurosci. 5:29. doi: 10.3389/fnint.2011.00029

Copyright (C) 2011 Schlaepfer, Bewernick, Kayser and Lenz. This is an open-access article subject to a non-exclusive license between the authors and Frontiers Media $S A$, which permits use, distribution and reproduction in other forums, provided the original authors and source are credited and other Frontiers conditions are complied with. 